\title{
Student Attitudes Toward Library Methods Courses in a University
}

Miss Wedemeyer is instructor, University of Maryland Library.

$\mathrm{R}$ ECENTLY, because of adverse criticism on the part of students in the campus newspaper, it became desirable to examine our library methods courses. Although some "griping" is normal among students, the situation had progressed beyond the healthy stage. Facts were needed in order to provide appropriate remedies.

The Courses. The library methods courses are designed to acquaint the students with the facilities of the university library, and to teach them the use of common research materials and reference books. The courses, Library Science $I$ and 2, are given during two consecutive semesters. The classes meet for one hour per week, and yield one semester hour of credit for each semester's work. The courses are required in most curricula in the College of Arts and Sciences. The textbooks used at the time this study was made were Zaidee Brown's Library Key ${ }^{1}$ and the Enoch Pratt Free Library's Reference Books. ${ }^{2}$ According to university records, the courses have been offered since the fall of $1919 .^{3}$

The Study. A questionnaire was used because the students' written opinions were wanted. Eight questions covered the following points: class status, major and minor fields, value of the courses in university

1 Brown, Zaidee, The Library Key: $7^{\text {th }}$ ed. New York, Wilson, r 949 .

${ }_{2}$ Enoch Pratt Free Library. Reference Books. $2 \mathrm{~d}$ ed. Compiled by Mary N. Barton. Baltimore, I95 I.

3 Maryland State College. Catalog I9I9-I920, p. I77. work, importance of each subject covered, time spent in preparation of assignments, and duplication of work in library and other courses. The study included only the opinions of students enrolled in the course. The bases for the questions were the four most common complaints made by the students. These complaints were: (I) the material presented does not warrant the length of time usually required for completing assignments outside of class (2) the material presented is to a large extent already known (3) the material is duplicated in other classes (4) there is no use for the material.

The questionnaire was given to $237 \mathrm{stu}-$ dents in May, 1952. The students were enrolled in Library Science 2 at the time. Signatures were not requested.

\section{Summary of the Study}

Answers to Question 4, concerned with the importance to the students of the subjects taught, were the most revealing as to student attitudes. This question is summarized in some detail; a brief statement only is made regarding the other questions.

Questions I, 2, 3. The answers to Question I, which dealt with class status, revealed that the classes were composed of $85.4 \%$ freshman and sophomore students, I $4.6 \%$ junior and senior students. The responses to Question 2 showed that Social Studies ${ }^{4}$ was either the major or minor

4 In this study social studies include sociology, politics and government, history, economics and geography. 
TABLE I

Ranking of Subjects Taught by Frequency of Answer

\begin{tabular}{|c|c|c|c|}
\hline \multicolumn{2}{|l|}{ Most Important } & \multicolumn{2}{|l|}{ Least Important } \\
\hline $\begin{array}{r}\text { Subject } \\
\text { Card Catalog }\end{array}$ & Frequency & $\begin{array}{l}\text { Subject } \\
\text { Parts of the Book }\end{array}$ & Frequency \\
\hline Periodical Indexes & 196 & Government Documents & 95 \\
\hline Reference Books in Special Fields & I 79 & Construction of a Bibliography & 88 \\
\hline Tour of the Library & I 55 & Dictionaries & 86 \\
\hline General Encyclopedias & I $3 \mathrm{I}$ & General Encyclopedias & 68 \\
\hline Indexes to Collections & I 28 & Classification of Books & 64 \\
\hline Classification of Books & I 26 & Indexes to Collections & 60 \\
\hline Yearbooks & 125 & Yearbooks & 58 \\
\hline Construction of a Bibliography & I2I & Tour of the Library & 39 \\
\hline Dictionaries & 94 & Reference Books in Special Fields & $3^{\mathrm{I}}$ \\
\hline Government Documents & 69 & Card Catalog & $2 \mathrm{I}$ \\
\hline Parts of the Book & 55 & Periodical Indexes & 18 \\
\hline Totals & I 580 & & $75 \mathrm{I}$ \\
\hline
\end{tabular}

field of the largest number of students. According to the students, the courses in which library methods proved most valuable were English first and Social Studies a "poor" second. Subjects for which the courses were said to be least valuable were sciences and languages.

Implications of these findings included: (I) determining what freshman and sophomore students are required to know about the library; (2) learning how best to meet the needs of junior and senior students; (3) knowing what provisions have to be made for graduate students; (4) finding out how to meet the problems of students majoring in the social sciences. Since the study was made, more individual assignments have apparently helped the junior and senior students in their work. Gaps in the collections are being filled, with Winchell's listings in Social Sciences used as a guide. ${ }^{\mathbf{5}}$ Selections are made with consultation of the Sociology and other departments of the university. ${ }^{6}$

Question 4. This question was stated as follows :

\footnotetext{
5 Winchell, Constance. Guide to Reference Books. 7th ed. Chicago, ALA, I 95 I. pp. I 48-2 I 5 .

6 It should be mentioned that many departments including Sociology were consulted in the fall of I95 I and asked for suggestions as to materials for presentation to the classes.
}

The subjects usually presented in Library Science 2 are listed below. In the appropriate columns to the right of the list check the items you feel are most important (in the sense of practical application) to your needs, those which you feel are least important, and those for which you have no reaction.

The students were further instructed to "Give an example, or make a statement to support your check marks."

Results and Conclusions. Table $\mathrm{I}$ is a summary of the students' checking. From the results of this table, the general conclusion can be drawn that a majority of the students $(55.6 \%)$ considered the subject matter of the course "most important" as compared to the students who considered it "least important" $(26.4 \%)$ or indicated apathy toward the subjects $(18 \%) .^{7}$ However, over one fourth of the opinions indicated that some of the subject matter was of least importance. It was necessary to discover why these opinions existed. There was also concern for the apathy, even though it represented but I $8 \%$.

The ranking of the subjects under "most important" follows the anticipated pattern, with the possible exceptions of "Tour of

7This percentage includes groups "No Reaction" and "Not Checked." These groups are not shown on Table I. 
Library" and "Yearbooks." It might have been expected that the "Tour" would be rated lower and "Yearbooks" higher. The ranking in "Least Important" indicates an almost perfect negative correlation with the ranking in "Most Important." Generally, subjects ranking high in the "Most Important" category were low in "No Reaction" or "Not Checked."

One may conclude that the first six items in the "Most Important" category in Table I meet with student approval as now presented. The last six need special study. The rankings in other categories in general substantiate this conclusion.

Reasons for Response. The statements made to support the check marks for each category were grouped into positive and negative statements. Statements were considered "positive" that indicated a gain in learning; "negative," those that indicated there was no gain. Statements were omitted in some instances. The statements indicating a gain in learning included such items as the following: learn the subject itself, knowledge is of general and/or specific application to university work, the knowledge saves time, the material is interesting and is new. The "negative" group included the opposites of these items, and also the observations that the subject was already known, and that instruction was too detailed.

A summary of the number and kinds of response is given in Table II.

The results indicate that less than one

TABLE II

Distribution of Positive, Negative and No Statement Reactions To Support Evaluation

\begin{tabular}{c|c|c}
\hline \hline Statement & Frequency & Percentage \\
Positive & I304 & 45.8 \\
Negative & 839 & 29.5 \\
No Statement & 701 & 24.7 \\
\hline Totals & 2844 & 100.0 \\
\hline
\end{tabular}

half show a gain in learning. One might have assumed that the number of "Positive" and the number of "Most Important" tabulations in Table I would agree. Since this was not the case, it might be in- . ferred that there are reasons other than the subject matter itself that led to the discrepancy. An implication is that something was wrong with the teaching method. There are other factors involved, but teaching is an immediate concern.

A comparison of the positive and negative answers reveals that many more students consider the material useful in general and specific application to university needs than consider it not useful; more students indicate that the material is already known than state it is new; interest has a low rating in both the positive and negative answers; duplication was mentioned in the negative responses.

The fact that the students were able to specify the usefulness of the material implied the need for the course. The negative aspects should be overcome. The problem of repetition of work learned elsewhere could be eliminated to a large extent through a screening test. Students who passed the test may be excused from the course. (Experience at Maryland in giving pre-tests at the beginning of the semester in Library Science I revealed that students answer correctly only about one third of the questions asked.) The aspect of duplication can also be overcome with careful planning among divisions of the university. The less tangible problem of interest brings us back again to a consideration of teaching method.

It should be kept in mind that the purpose of the course is to teach students to use the library, and not to train professional librarians. Knowledge of students as human beings is essential in this approach. 
Books, ${ }^{8}$ staff meetings, observations of other teachers on the campus (with their permission, of course) consultation with members of the staff of the College of Education should help with the problem. Above all, close observation of the student at work in the library gives first hand information as to type of information he needs and his problems in locating the material. All of the instructors with one exception are assigned to desk duty.

Some of the specific measures taken to make the material more meaningful to the students, while not world shattering, have helped. An unused upper floor of a temporary building is available for supervised student use of materials discussed in class. This supervised use of the indexes, yearbooks and other materials has allowed us to do away with the out-of-class assigned work.

Because of mechanical problems, motion pictures or slides could not be used. Cards have been used successfully in teaching the card catalog. One card was cut into pieces, showing author, imprint, etc. These parts were displayed on a flock board piece by piece and the use and meaning of each explained. The other card was left intact so that the "whole" might be seen readily. This examination of parts was also found helpful in "translating" the items on a catalog card into acceptable bibliographical form.

For items rated consistently low by the students, various approaches have been devised. In the case of government documents, popular magazines have been helpful. A case in point is the article which appeared entitled "Uncle Sam Has the An-

${ }^{8}$ Books that have proved helpful are:

Cole, Luella. The Background for College Training. New York, Farrar \& Rinehart [cr940]. U.S. President's Commission on Higher Education. Higher Education for American Democracy, a Report. Washington, U.S. Government Printing Office, r 947 . Wilson, Louis, The L.ibrary in College Instruction; a Syllabus on the The L.ibrary in College Instruction; a Syllabus on the swers," Parts of the book, also of low rating, have been presented in conjunction with other assignments.

The answers to Question 4 suggest that "detail" and "time spent" in presenting material are important, positive aspects of the student's learning process. The raison d'étre of obviously useful materials, for example, government documents and yearbooks, has not always been made clear to the students. Items rated low by the students require careful consideration.

Questions 5 and 6. These questions were designed to measure the intensity of the rating in Question 4.

Question 7. This question concerned the time spent in preparation for library science assignments. The results indicated that too much time was spent in comparison with time spent on other subjects. As a consequence, the assigned work was cut down, much was completed in the supervised periods mentioned above.

Question 8. This question regarded duplication of work presented in the library courses and in other courses. The students were asked to indicate which presentation was "better" or "worse" and to give reasons. Various duplications were listed; the subject receiving the largest number was bibliography with 184 . The library science presentation received I 13 "better" answers. The reasons given substantiate answers in Question 4, namely, more detailed instruction and more time spent on the subject. The students also mentioned the mimeographed form used in the library courses as helpful. The "worse" answers mentioned confusion on the part of the students because of the different forms used on the campus. (Two meetings were held with a member of the English Department staff.

\footnotetext{
Use. New York, Wilson, r 951 .

$\checkmark$ Lewis, Rose G., In Family Circle Magazine, March, 1 953, pp. I33-1 34 .
} 
A bibliographic form acceptable to both departments was worked out.) This problem of duplication needs further study.

\section{Conclusion}

One overall benefit from the study was the revelation of tangible evidence of the strength and weakness of our efforts to teach the students something about the use of library resources. More specifically, we learned that some of our preconceived concepts concerning the student attitudes were wrong, some were right. Conclusions concerning the four items mentioned earlier are as follows:

I. Too much time spent on assigned work seemed to be proven correct, and we have tried to rectify this situation by shorter and more practical assignments.

2. The fact that the material is to a large extent already known was mentioned by a comparatively few students. The problem warrants further study. A "screening" test may be indicated.

3. That there is duplication of work in Library Science courses and other courses has been proven true. To eliminate all duplication of work in courses offered in a large university is perhaps impossible. Duplication in the broad sense of "overlearning" is not necessarily detrimental to the best interests of the students. As one English instructor put it, "The more times the students are told about the dictionary the better!" However, in the specific instance of bibliography and the dictionary it is possible for the library to arrange with the English Department a program that will reduce duplication of subject matter.

4. That there is little use for the material seems to have been proven false. The students indicated that the material was useful.

Beyond these four points, the fact that there might be something wrong with the presentation of the material was brought out in the answers to Question 4. The need for clearer presentation to the students of the purpose of each subject taught should eliminate some of the confusion evident in answers to Question 4.

The director of libraries has appointed a committee composed of four instructors in library science to make an intensive study of the library's instructional program. This committee is at work on five major points: ( I) the provision for instruction for upperclass and graduate students; (2) the expansion of the program to include students not now included. Requests for special lectures on library procedure by the Colleges of Education, Home Economics and Agriculture make it clear that instruction is needed in these colleges. At the present time only students in the College of Arts and Sciences are required to take the courses. The committee is attempting to determine what changes must be made in the courses in order to satisfy the needs of the student body as a whole; (3) The reduction in duplication of effort by the English Department and the library especially in the fields of bibliography and dictionary study; (4) Provision for more extensive use of visual aids; (5) A study of the students' problems of adjustment.

A set of slides showing how periodical information may be obtained from the University of Maryland library has been made. Two of the students in the library science courses and a photographer from the College of Home Economics assisted in making the slides. Preliminary consultations with the English Department have been held. Much needs to be done. This study has given us a point of reference from which to plan for better library instruction for the students. We shall continue to make every effort to understand as thoroughly as possible all aspects of the problem that confronts us so that we may be able to work out a satisfactory solution. 